\title{
Grundlinien der Anerkennung im Raum der Freiheit, der Sicherheit und des Rechts
}

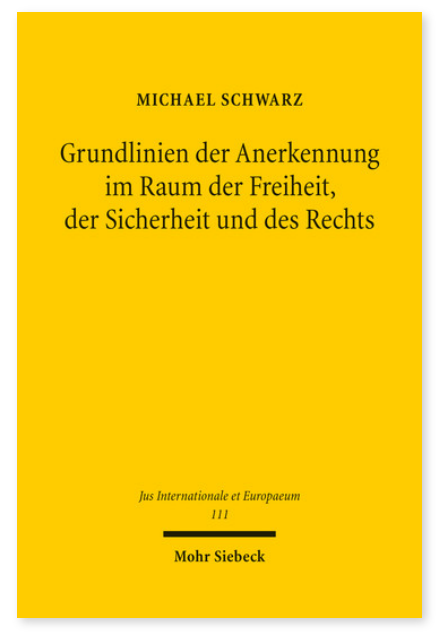

2016. XV, 441 Seiten. JusIntEu 111

ISBN 978-3-16-154209-1

eBook PDF $94,00 €$

ISBN 978-3-16-154208-4

fadengeheftete Broschur $94,00 €$
Die Rechtsform der Anerkennung bewegt sich im Spannungsfeld von Einheit und Vielfalt und bildet eine Schlüsselkategorie föderaler politischer Systeme. Sie ist Fluchtpunkt der Integration des gemeineuropäischen Raums der Freiheit, der Sicherheit und des Rechts, welcher eine wachsende Anzahl sensibler Politikbereiche über nationale Jurisdiktionsgrenzen hinweg verbindet. Michael Schwarz zeigt die Sollbruchstellen der Legitimität unionsrechtlicher Anerkennungsregimes in föderaler, rechtsstaatlicher und demokratietheoretischer Dimension auf. Dabei wird die Anerkennung auf ihre Anfangsgründe im Binnenmarkt zurückgeführt, ihre legislative Fortschreibung im neuen Bezugsrahmen des Raums der Freiheit, der Sicherheit und des Rechts kritisiert und vor einer föderalen Hintergrundfolie legitimatorisch rekonstruiert.

Michael Schwarz Geboren 1984; Studium der Rechtswissenschaften an der Humboldt-Universität zu Berlin; 2013 LL.M. in legal theory an der New York University; 2014 Promotion an der Humboldt-Universität zu Berlin; derzeit Rechtsreferendar am Kammergericht Berlin.
Jetzt bestellen:

https://mohrsiebeck.com/buch/grundlinien-der-anerkennung-im-raum-der-freiheit-der-sicherheit-und-des-rechts9783161542091?no_cache=1

order@mohrsiebeck.com

Telefon: +49 (0)7071-923-17

Telefax: +49(0)7071-51104 